\title{
Historicidade e Contexto em Perspectiva Histórica e Comunicacional'
}

\section{Historicity and Context in a Historical and Communicational Perspective}

\section{Marialva Carlos Barbosa}

Professora do Programa de Pós-Graduação em Comunicação da Universidade Federal do Rio de Janeiro (UFRJ), presidente da INTERCOM.

$<$ marialva153@gmail.com>

\section{Ana Regina Rêgo}

Professora e Coordenadora do Programa de Pós-Graduação em Comunicação da Universidade Federal do Piauí (UFPI), presidente da ALCAR.

<anareginarego@gmail.com>

\section{RESUMO}

Este artigo dedica-se a abordar os conceitos de Historicidade e Contexto e sua aplicabilidade no ambiente da historiografia e da comunicação. Partimos de uma revisão de literatura para desvendar os caminhos do conceito de historicidade a partir da Fenomenologia no ambiente da Filosofia e sua visualização, compreensão e aplicabilidade pelos historiadores. Posteriormente, explicitamos o conceito de contexto na história e na comunicação e, por fim, chegamos aos modos de comunicação dos escravos brasileiros, como ponto inflexivo de aplicabilidade da questão histórica e conceitual. Seu mundo, suas sociabilidades, formas e agir comunicativo, assim como manifestações culturais, dão visualidade aos conceitos mencionados. O processo metodológico é qualitativo e pautado na potencialidade de interseção entre os campos teóricos visitados e o espaço empírico observado.

\begin{abstract}
This article focuses on the concepts of Historicity and Context and its applicability in the historiography and communication environment. It starts from a literature review, made so to unveil the paths of the concept of historicity from the Phenomenology, present in the environment of Philosophy as its visualization, understanding and applicability by the historians. Subsequently, we explained the concept of context found in history and communication, and finally, we address the brazilian slaves modes of communication, as an inflexible point of applicability of the historical and conceptual question. Their world, their social abilities, shapes and communicative action, as well as, cultural manifestations which give notoriety to the, already mentioned, concepts. The methodological process is qualitative and based on the potentiality of intersection between the theoretical fields visited and the observed empirical space.
\end{abstract}

Keywords: Historicity. Context. Communication.

\section{Introdução}

Durante muito tempo, a história que veio a se perpetuar no campo do discurso foi a história dos vencedores. Os vencidos, em sua maioria, foram apagados e muitas sociedades chegaram a desaparecer. Povos dominados, obrigados a esquecer a própria língua e a relegar a própria cultura ao

1 Pesquisa financiada por CNPQ e CAPES. 
esquecimento, em prol do modelo de civilidade do dominador; foram soterrados em camadas e camadas de informações e discursos construídos e visibilizados em narrativas a partir dos que detinham o poder de falar.

Religiões, práticas culturais, costumes, formas de relacionamentos e sociabilidades foram impostos às sociedades dos que não tiveram condições de se colocar como vencedores. Na maioria dos processos de dominação encontramos não só o desejo por mais poder, político e econômico, mas também a superioridade bélica possibilitada por alguma forma de tecnologia.

Contudo, a tensionalidade do campo cultural induz a uma resistência latente dos vencidos que muitas vezes introduzem de forma velada e calada, através de práticas e manifestações, vestígios de um presente do passado de seus próprios povos, que terminam sendo apropriados ou simplesmente assimilados pelos vencedores. As religiões trilham também esse caminho, mas não só as religiões, a própria hibridação linguística e cultural revela as possibilidades díspares que se colocam quando encontros culturais, na perspectiva de Burke (2005), acontecem.

Foi reconhecendo que a história em seu campo do vivido não se faz somente de vencedores, mas também de vencidos e dominados, que o próprio campo da historiografia se voltou para a construção de uma história vista de baixo, e de uma micro-história, numa alusão a Ginzburg (1989), com possibilidade de se trabalhar com novos objetos, levantando problemas antes não trabalhos e adotando novas abordagens, antes não possíveis no campo, numa referência à obra organizada por Nora e Le Goff (1974).

Nesse panorama, percebe-se que as mudanças na condução do processo de análise e do registro histórico, possibilitadas não somente pelo trabalho dos historiadores franceses, mas pela própria evolução dos métodos e exigências sociais do historiador, proporcionaram ainda a abertura de novos focos de interesse, antes centrados na política e que a partir de então se abriram para cultura, religião, jornalismo, dentre outros temas, sempre com enfoque mais socializado e democrático. Ocorreu, desse modo, um alargamento do conceito de historicidade, como também um deslocamento do lócus histórico, agora em um ambiente multidisciplinar de cultura (Rêgo, 2010, p. 13).

De todo modo, não é nossa intenção fazermos aqui uma história do campo da historiografia. Nos basta reconhecer que a abertura possibilitada no século XX pelos historiadores franceses e alemães trouxe também indagações aos demais campos com relação ao discurso histórico produzido até então.

$\mathrm{Na}$ filosofia, por exemplo, se iniciou todo um processo em que se contestava a representatividade da história do próprio campo. Heidegger (2005), na esteira de Hegel, contesta o status quo vigente sobre a verdade da história e a 
história da filosofia afirmando que não é na ciência historiográfica que se deve buscar a história, mas é somente na localização do modo de ser da história, que revela a condição do ser histórico, a historicidade em sua temporalidade, que a história pode se manifestar e se tornar objeto da historiografia. Nas palavras do autor citado por Ricoeur (2012, p. 381) “[...] nosso próximo objetivo é encontrar o ponto de partida para a questão ordinária da essência da História". Todavia, como bem afirma Ricoeur (s/a, p. 12), Heidegger buscava reorientar e reeducar o nosso olhar para que "[...] subordinássemos o conhecimento histórico à compreensão ontológica".

A temática da historicidade renasceu anos depois tanto no ambiente da historiografia, como no campo da filosofia. E, se como afirmam Ricoeur (2012, p. 393) e Koselleck (2014, p. 278) a historicidade (Geschichtlichkeit) como proposta por Heidegger não responde as questões da história; ela ao certo suscita possibilidades de trabalho que se colocam entre o "ter sido" e o "não ser mais", em uma dialética de presença e de ausência em que o histórico intramundano se subordina ao "[...] histórico primordial que somos enquanto seres de preocupação" (Ricoeur, 2012, p. 389).

Koselleck, no entanto, alerta:

A atual discussão em torno da chamada historicidade enfrenta desafios teóricos que resultaram da crise do historicismo. 0 conceito de historicidade pretende deter o processo de relativização permanente do qual o historicismo era acusado. A historicidade absolutiza a relatividade, se me permitem essa expressão um tanto absurda. Aqui, é evidente a influência de Heidegger, apesar de ele não ter feito muito para avançar o debate em nossa ciência. Já em Ser e Tempo, ele abstrai quase completamente a história; a historicidade é uma categoria da existência humana, mas sem abordar estruturas interpessoais ou supraindividuais. Diante da temporalidade da história, Heidegger aponta o caminho da finitude da existência, mas não prossegue nele. Por isso, por trás do uso da fértil categoria da historicidade, jaz, de um lado, o perigo de uma ontologia transhistórica, como a desenvolvida por August Brunner; de outro, na aplicação da filosofia de Heidegger à história- onde a filosofia passa a adquirir um tom escatológico como história do ser-, não por acaso transparecem esquemas histórico-filosóficos tradicionais de declínio e ascensão (Koselleck, 2014, p. 278).

Seguindo essa trilha, tentaremos fugir das armadilhas possíveis e nos concentraremos em uma historicidade que vem, portanto, a ser um fio condutor da narrativa que pretende desvelar lacunas localizadas nos e entre os espaços de experiências e horizontes de expectativas, como nos propõe Koselleck (2014). Tendo como motivação primeira, as possibilidades de localização de 
novos sentidos do histórico que possam sanar os espaços de esquecimento na historiografia da comunicação, a partir da adoção de uma perspectiva interpretativa das narrativas guardadas na memória do campo do vivido e confrontadas com as narrativas da historiografia.

Essa escolha pressupõe uma tentativa de conciliação entre as tensões estruturais existentes entre a historiografia e a historicidade. Desse modo, em um primeiro momento nos concentramos na trajetória da construção do conceito de historicidade e sua relação com a construção dos contextos; já em um segundo momento abordamos a noção de contexto no ambiente da história para ao final nos debruçamos sobre a historicidade dos escravos brasileiros, identificada através das manifestações dos modos de agir, viver e se comunicar das comunidades composta por negros escravizados, em que o contexto de interlocução permitiu a inteligibilidade de suas particularidades enquanto corpo social atuante, em um espaço-tempo definido, possibilitando após a escavação de documentos, rastros, vestígios, uma interação possível entre aquela ordem vigente e a constituição de uma história dos que ainda não tiveram a oportunidade de escrever sua própria história.

\section{Historicidade: um conceito em construção}

A historicidade enquanto verbalização da essência do histórico nasce na tensão entre a filosofia e a história, marcando disputas entre estes campos, ao tempo em que se constitui, como estrutura de tensão e, em antítese, de aproximação entre filósofos que se dedicam ao campo da história e historiadores. Hegel (2008, p. 18) chama atenção de modo direto, para a racionalidade histórica, alertando aos filósofos que não devem considerar a história como ela é, mas devem ter cuidado ao tratar com o campo histórico, pois em sua visão os historiadores praticavam o que denomina de invenções ainda que somente acusassem os filósofos desse tipo de prática.

Nas primeiras defesas de uma historicidade nascente, Hegel confronta os campos filosófico e histórico e trabalha a historicidade da razão no contexto da Revolução Francesa; evento que para esse filósofo constituiu-se tendo como pano de fundo a razão filosófica a partir do pensamento de Kant e Rousseau e, não a razão histórica. Essa diferença, segundo Hegel fez o movimento de 1789 irromper a estrutura da cotidianidade de modo ímpar, propondo uma nova dimensão para a história.

De certo modo, Hegel propõe uma alternativa à história, sobretudo da filosofia, que estaria em sua visão condenada. Essa alternativa teria base na historicidade e na verdade da própria filosofia. Todavia, a proposição hegeliana para a história da filosofia traria, em suma, uma história racionalmente 
compreendida, em que razão e historicidade pudessem se interligar, embora o êxito desse relacionamento fosse difícil e com consequências para a historicidade. Iber (2013, p. 28) reconhece que "Hegel não deixou a razão ao todo com a negatividade e a historicidade, porque ele teve interesse em uma história racionalmente compreendida, que se destina à unificação e reconciliação". Assim, embora Hegel, "não desnegue a historicidade da razão", ele almeja a partir de uma posição filosófico-histórica, uma razão histórico-filosoficamente integradora em que se localiza a historicidade e, portanto a história.

Ao priorizar a racionalidade como guia para a liberdade e para a construção histórica, Hegel consolida um pensamento que servirá de embasamento para outras abordagens sobre historicidade. Para Hegel, a razão-lógica se coloca sempre em relação com o tempo e a história.

Hegel insere assim a história da filosofia numa verdade consumada pela razão. Já em outra perspectiva, o autor mencionado trabalha a temporalização da verdade e interliga historicidade e temporalidade, portanto a contextualidade do ser histórico.

Heidegger, por sua vez, ao buscar o sentido do ser e a verdade da filosofia em sua obra Ser e Tempo, traz a historicidade para o protagonismo de seu pensamento. Para esse autor, somente na temporalidade acontecem movimentação e permanência específicas da presença. O acontecer da "presença" reúne especificamente as condições existenciais e temporais que possibilitam uma compreensão da historicidade. Portanto, em certa medida para Heidegger (2005) o ser em essência é pre-sença, mas Sartre (2015, p. 19) alerta que a "[...] ausência também revela o ser, já que não estar aí é ainda ser".

Sobre a questão histórica, Heidegger (2005, p. 180) afirma que não se deve buscá-la na historiografia, mas somente na historicidade que seria o modo de ser da história, e no inter-relacionamento da historicidade com a própria temporalidade. Somente aí que se poderia concluir como a história poderia se tornar objeto da historiografia.

Na perspectiva deste autor, a historicidade somente ganha sentido em sua temporalidade, o que justificaria sua construção fenomenológica, como também a compreensão de sua possibilidade ontológico-existencial que deve se constituir em oposição a uma compreensão vulgar da história da presença, embora a construção da própria historicidade seja perpassada por essa vulgaridade (Heidegger, 2005, p. 180).

A historicidade é, portanto, a chave para a compreensão da pre-sença do ser e não se propõe como temporal porque está na história, mas contrariamente, só pode entrar para a historiografia porque é temporal. 
A compreensão da história, portanto, estaria relacionada ao acontecer e dar a conhecer da pre-sença em sua temporalidade. Essa possibilidade de abertura da historiografia da história se faria possível a partir, portanto, da filosofia. "A interpretação existencial da historiografia, como ciência, visa, unicamente, a comprovar a sua proveniência ontológica da historicidade da pre-sença" (Heidegger, 2005, p. 181).

Heidegger (2005, p. 184) enfatiza que tudo o que possui um sentido histórico encontra-se em um devir, logo, o que tem história pode fazer história. Em suas palavras, é " "fazendo época" que, no "presente", se determina um "futuro". História significa, aqui, um "conjunto de acontecimentos e influências" que atravessa "passado", "presente" e "futuro". Aqui, o passado não tem primazia.

Então, se a história está contida no ser da pre-sença eem sua temporalidade, o conhecimento sobre a historicidade própria da pre-sença deve ter início no reconhecimento do que é histórico e possui sentido temporal. E assim Heidegger segue contestando o protagonismo do passado na historiografia.

Em suma, para Heidegger, a historicidade encontra-se sempre relacionada à existência do ser no mundo. Todo acontecer histórico implica em um acontecer do ser-no-mundo. Portanto, a historicidade do ser é também a historicidade do mundo temporalizada em sua temporalidade.

Nesse sentido, para esse autor, se a historiografia tem sua origem na historicidade, ou seja, no ser histórico, é somente a partir da historicidade que se pode determinar os objetos da historiografia. Logo, o "nascimento" da historiografia a partir da historicidade própria significa, então: que a tematização primária do objeto histórico projeta a pre-sença que vigora por ter sido presente em sua possibilidade mais própria de existir" (Heidegger, 2005, p. 201).

Iber (2013), ao analisar a abordagem da historicidade em Hegel e Heidegger, alerta para os problemas da teoria da historicidade nos dois autores, que provém dos conceitos que ambos possuem de filosofia, que seria estreito demais. "O fundamentalismo da razão de Hegel abre a razão muito pouco à relação ao seu outro", enquanto, a "[...] reconstrução histórica de ser de Heidegger da história da filosofia em ordem ao outro da racionalidade leva em consideração muito pouco os potenciais da racionalidade residindo na história da filosofia" (Iber, 2013, p. 33).

Já Gadamer, ao analisar a obra dos dois filósofos, enfatiza aspectos na obra de Heidegger, que extrapolam uma mera visão sobre a historicidade, mas se concentra em superar a metafísica, portanto, numa ultrapassagem de uma transcendência da experiência sensível, 


\begin{abstract}
Quando Heidegger fala sobre a consumação da metafísica por meio de, Hegel, porém, ele não tem em vista o mero fato histórico, mas está formulando ao mesmo tempo uma tarefa, que ele denomina a superação da metafísica. [...] Superar significa muito mais, tal como Heidegger o formulou de maneira inimitável de seu próprio pensamento, sempre ao mesmo tempo uma transversão dametafísica. Aquilo que se transverte não se encontra simplesmente atrás de nós (Gadamer, 2012, p. 122).
\end{abstract}

Para Iber (2013), entretanto, Heidegger pratica uma compressão da história da filosofia para com a história da metafísica dando primazia ao começo, ao mesmo tempo, em que preconiza o final da metafísica. Seu interesse volta-se não apenas para"[...] as formas diversas da racionalidade de desenvolver o sendo, mas para a repreensão geral do outro da racionalidade que foi encoberto na história da metafísica desde o princípio" (Iber, 2013, p. 30). Esse autor ainda ressalta que mesmo com a tendência a positivar o destino do ser como metafísico, Heidegger aponta que a história da racionalidade ocidental também possui vertentes "[...] no esquecimento de seu fundamento não-racional" (Iber, 2013, p. 30).

Ricoeur também nos fornece uma visão ampla acerca da trajetória do conceito de historicidade e de sua relação com a temporalidade, tendo como ponto de reflexão a obra de Heidegger já aqui referenciada. Em A Memória, a História e o Esquecimento, o autor trabalha alguns pontos do pensamento heideggeriano contidos em Ser e Tempo, dentre eles a questão da temporalidade e o intrínseco relacionamento com a historicidade.

Inicialmente, Ricoeur esclarece os problemas apontados por Heidegger e que contrapõem a interpretação à procura pela verdade na história. Para este autor, as "[...] dificuldades não se devem principalmente à inevitável intervenção da subjetividade da história, mas à posição temporal entre o momento do acontecimento e o da narrativa que o relata" (Ricoeur, 2012, p. 350). É, portanto, a crítica hermenêutica que o leva a uma abordagem entre historicidade e temporalidade. Inicialmente, ele trabalha com a temporalidade e já inicia com Agostinho e Heidegger. Vale lembrar que Agostinho é um dos seus guias em Tempo e Narrativa. Naquela obra, Ricoeur entrelaça o tempo Agostiniano com a intriga aristotélica; aqui, ele trata de correlacionar as abordagens de Heidegger e Agostinho e começa abordando o tema da tridimensionalidade da temporalidade da alma, assim, ao tratar a problemática da presença do ausente o autor pondera,

Em Santo Agostinho, o segundo tema adquire uma forma com a qual Heidegger rompe de maneira decisiva: a igual primordialidade das três instâncias temporais que se distribuem a partir de um centro que é o presente. É o presente que explode em três direções, 
reduplicando-se, a cada vez, de certa forma: "Existem três tempos: o passado, o presente, o futuro". Ora, "o presente do passado, é a memória; o presente do presente, é a visão (contuitus) [teremos, mais adiante, attentio]; o presente do futuro é a expectativa" (Ricoeur, 2012, p. 364).

Para pensar a temporalidade, Ricoeur recorre e confronta o Daisen heideggeriano, em o "ser-para-a-morte" no ambiente da história. Lembrando que Heidegger associa a consciência moral à necessidade de atestação, em que esta última seria a instância da verdade somente verificada em inflexão dos verbos no tempo presente, inclusive, através de testemunhos. Essa visão, lembra Ricoeur, foi alargada por Heidegger que propõe um poder-ser, uma antecipação da condição de atestação no futuro. A antecipação seria a responsável pela definição do passado, desde que o pretérito seja considerado como "tendo sido" e não como desaparecido.

Ricoeur traduz então a influência Heideggeriana na condução da operação historiográfica, visto que historiadores também passaram não mais considerar o passado como algo dado, e, sim, como um espaço passível de reconstrução permanente. Como também demonstra sua clara preocupação com a hierarquização das instâncias temporais tal como proposto em Ser $e$ Tempo, em que temporalidade fundamental, historicidade e intratemporalidade são postas em confronto com a autenticidade histórica.

Ao tratar a historicidade, Ricoeur também concentra sua análise e crítica em Heidegger, que, ao contestar a história-ciência, disseca quatro sentidos iniciais para história (inicialmente a visualidade do passado como algo dado e não mais disponível para o trabalho; posteriormente o passado como atuante; como também a história como a soma das coisas transmitidas e, por fim, a tradição) com a intenção de desvelar o "provir".

Rastros e vestígios são contestados por Heidegger (citado por Ricoeur, 2012), pois só podem ser relacionados ao passado se for possível relacioná-los ao ambiente do ter-sido. O Dasein, ou o ser-no-mundo, por sua vez, não pode ser enquadrado como passado, porque mesmo não podendo se apresentar de forma concreta, pertence ao ter-sido, entretanto, ainda é, portanto, existe.

Ricoeur assinala que a dialética da presença e da ausência poderia ser confrontada com a noção de vestígio em Heidegger, enquanto que a existência do ter-sido e a possibilidade do manejo deste mesmo ter-sido, se confrontados não permitiram o reconhecimento do rastro, pois a "[...] noção de vestígio, ampliada à de rastro, poderia então dar azo a uma discussão que levaria em conta a dimensão veritativa do ato mnemônico e do ato historiográfico"(Ricoeur, 2012, p. 389), entretanto, Heidegger limita-se a "[...] reinserção obstinada da 
dependência da historicidade acerca da temporalidade fundamental pela evocação de traços resultantes da dependência do ser histórico em relação ao mundo" (Ricoeur, 2012, p. 389).

O historiador, por exemplo, poderia retornar ao passado a partir de qualquer momento do presente e objetivando chegar até qualquer momento do passado. Portanto, um retorno a um presente do passado, como tendo sido vivido por seus contemporâneos. Na verdade formula-se a possibilidade de quebrar o determinismo histórico. Neste ínterim, Ricoeur reconhece que a "[...] história dos historiadores não está, portanto, condenada à historicidade inautêntica que Heidegger declara "cega às possibilidades", como o seria uma historiografia fechada numa atitude museográfica" (Ricoeur, 2012, p. 393).

Todavia, vale ponderar que é em Heidegger e sua busca pelo sentido do ser e da verdade histórica e filosófica, como também em sua proposta relação entre historicidade e temporalidade que Ricoeur se inspira para trabalhar tempo e narrativa; como também é em Heidegger que virá a se inspirar para desenvolver os conceitos de identidade narrativa e ação narrada, com a ressalva de que a Hermenêutica ricoeuriana diverge em grande medida da Hermenêutica heideggeriana, sobretudo, na potencialização da compreensão tendo como ponto de partida a linguagem.

Já o historiador alemão Reinhart Koselleck, embora reconheça as limitações das contribuições do conceito heideggeriano de historicidade para a ciência histórica, assim entendida por ele, reconhece que, com a historicidade, é possível pensar uma ciência história" [...] que não investiga o movimento, mas a mobilidade, não a mudança no sentido concreto, mas a mutabilidade" (Koselleck, 2014, p. 278). É, portanto, numa diacronia atemporal que se pauta o conceito. São as possibilidades postas de transformações que se colocam não fora do tempo, mas para além do tempo que se consolidam como essencialmente históricas. "Muitos critérios formais de ação e de sofrimento históricos servem para decifrar a história de modo atemporal, num sentido transversal à própria história" (Koselleck, 2014, p. 278).

Koselleck enfatiza que a historicidade tem como intuito tanto assinalar a essência do histórico como o também o lugar da pesquisa histórica. "Ela livra o historiador da acusação de uma suposta subjetividade, da qual ele nunca escaparia, já que a "história" ultrapassa constantemente tanto o historiador quanto a ciência da história" (Koselleck, 2014, p. 279). Esse ponto de vista possibilita uma flexibilidade ao ofício do historiador através da transcendência da história que termina forçando os historiadores a uma reescrita permanente da narrativa historiográfica. "Com isso, a reformulação da história deixa de ser apenas uma correção de erros ou um ato de reparação, para tornar-se uma 
precondição da nossa profissão - contanto que a história da ciência histórica seja transcendente" (Koselleck, 2014, p. 279). Para esse autor, é a historicidade que articula as condições da essência do histórico, portanto, as possibilidades históricas, como também, da ciência histórica.

É ainda Koselleck que propõe que a ciência histórica tenha como ponto focal uma teoria dos tempos históricos que vem auxiliar a condução científica da operação historiográfica.

Assim como Heidegger, Koselleck se opõe a tridimensionalidade do tempo (passado, presente e futuro) e, sobretudo, se opõe à sequência cronológica que ordena a produção científica em história. "É evidente que esse esquema não contribui diretamente para a relação entre duração e evento. Antes precisamos aprender a descobrir a simultaneidade do assincrônico em nossa própria história" (Koselleck, 2014, p. 285). Desse modo, o autor levanta os possíveis questionamentos sobre a assincronia do simultâneo e dos conflitos históricos.

Essa linha de pensamento aponta a possibilidade de caminhos díspares para se pensar as contextualidades situadas em seus espaços e temporalidades, obviamente, reconhecendo os estágios de estruturas de relacionamento e de desenvolvimento de cada sociedade. Isso de certo modo, derruba por terra as pretensões de uma história geral ou global, haja vista, que as vivências e experiências de cada sociedade divergem temporalmente, tanto quanto espacialmente, e são marcadas com distintas marcas de historicidade que se constituem em seus próprios contextos constitutivos e constituídos.

Pensar, portanto, a história de uma sociedade, significa pensar em seus contextos, logo, pensar o tempo que é objeto da história e revelar suas mudanças e mobilidades em cada espaço.

O discurso sobre o contexto está, portanto, relacionado a duas questões primordiais: a verdade da ciência, em nosso caso da história, e o método e apuração e construção discursiva do próprio contexto, que influenciará diretamente na percepção do pesquisador e na narrativa que se constituirá ao final da investigação científica ou da operação historiográfica.

O contexto é, do nosso ponto de vista, intrínseco ao campo da história e aos objetos analisados. É o ambiente em que se constitui a essência das mutações, dos acontecimentos e de constituição dos próprios campos. Constituir uma narrativa acerca de uma existência passada pressupõe um esforço de inteligibilidade que mobilize não somente fontes, rastros, vestígios passíveis de acesso e manipulação, mas também a mobilização de artifícios da linguagem do presente que possibilitem a configuração e compreensão do que foi, como ainda sendo (visto o poder transformador da linguagem), pois se forma somente a partir de uma preocupação do presente que busca legitimar 
um passado tendo como referente uma determinada ordem do presente. Vale ressaltar que a linguagem manipulada para conformação das narrativas possui suas próprias normas de inteligibilidade pautadas nas regras da linguagem que se moldam às sociabilidades vigentes e não passadas.

O contexto é, assim, o lugar em que existências passadas, acontecimentos, fatos etc., em movimentos específicos, inscrevem e conquistam através da historicidade manifesta da essência, seu lugar na história. Portanto, procurar pelo onde, pelo quando e pelo como, das mutações, ondulações, permanências e rupturas, vai além de uma busca pautada em um mito da origem, mas se inspira em procurar por uma articulação de forças que fez com que surgissem e eclodissem de forma sistêmica. Essas forças se localizam no contexto, mas é somente a narrativa concordante que delas se faz, que o configuram na cena histórica. São os artifícios de constituição da compreensão, mobilizados e transformados em narrativas, que o tornaram ou não, um contexto válido para o acontecimento analisado no ambiente histórico.

Assim, tanto a pré-estrutura de compreensão do círculo hermenêutico heideggeriano, que, aliada à interpretação proposta pelo mesmo autor, são conformadoras de uma possiblidade de narrativa sobre existências e essências, para nós passadas, como a proposição de Ricoeur (2010) e seu círculo que leva o narrador a uma concordância discordante, revelada na ação das três mímesis em que os estágios de pré-figuração, configuração e refiguração se alternam, são importantes para compreensão do contexto como ambiente intrínseco ao objeto analisado. As estruturas que possibilitam uma pré-compreensão se mostram necessárias, porém, é a interpretação ${ }^{2}$ realizada a partir do lugar social (Certeau, 2011) do pesquisador que definirá a constituição dos prismas através dos quais a narrativa inteligível do acontecimento analisado e seu contexto se apresentarão ao leitor em terceira mímesis.

As características que ligam essência e acontecimento da existência não se dissociam do contexto, porque, como dito, são intrínsecos e indissociáveis. Contudo, é a linguagem que possibilita a inteligibilidade do ambiente e faz nascer a narrativa que define seu contorno. No item seguinte aprofundaremos a questão do contexto na história, assim como no campo da comunicação.

\section{O contexto na perspectiva histórica e comunicacional}

Quando se fala em contexto numa perspectiva histórica, seria lógico supor que estaria sob foco o que pode ser presumido como mundo lá fora. A

2 Para Heidegger (2006, p. 209), a interpretação é na verdade a elaboração que a presença realiza ao compreender e projetar seu ser para possibilidades e aberturas, portanto, a interpretação nasce do compreender e não vice-versa. 
partir da escolha de que vai ser analisado, poderia se pensar que as dimensões econômica, política, social etc. que formariam uma espécie de pano de fundo para o processo que se quer estudar.

Entretanto, pensar o contexto histórico não significa meramente condicionar a análise a essa dimensão exterior que, muitas vezes, poucos nexos possui com o objeto de pesquisa eleito.

É comum nos estudos que abordam os meios de comunicação a adição de maneira abrangente de um capítulo introdutório em que a dimensão histórica aparece como mera ilustração do tempo. Ora como um contexto exterior, ora abordando a história como simples apêndice ilustrativo.

Ocontexto não pode ser separado do texto, ou seja, daquiloque seencontra como condição da pesquisa. Assim, ao estudar historicamente os meios de comunicação, o texto seria os próprios meios e o contexto os processos históricos envolvidos no percurso da análise. Esses se referem às rupturas e às permanências através das quais a questão histórica deve ser considerada. O que estamos afirmandoéa existênciadeumcontextocomunicacionalenvolvidonaconstituição dos processos midiáticos e que deve ser analisado em toda a sua complexidade.

Se essa é uma premissa fundamental, pensar o contexto é também inserir na reflexão a relação particular com o tempo que a história possui no âmbito das ciências humanas. Revelando realidades empíricas já desaparecidas, colocando-as em confronto e relacionando-as ao presente, para a história a categoria tempo é definidora de sua condição como ciência.

Assim, a relação passado, presente e futuro condicionante da visão histórica pressupõe um distanciamento em relação ao passado para que esse possa ser visto na suposição de sua integralidade e com as características peculiares da existência vivida naquele momento histórico. O passado deve ser considerado como ícone de reconhecimento de ações humanas daqueles que viveram momentos históricos particulares no tempo de suas ações, e é assim que podem ser reinterpretados.

Não se pode comparar passado e presente, nem lançar interpretações em relação a um futuro que só existe, a partir do presente, como interrogação e dúvida. Por outro lado, devemos considerar que o futuro dos homens de outrora é o presente onde nos movemos.

A história, ao ter o passado como foco de suas abordagens, realiza uma intepretação sobre a ação humana no tempo de sua produção a partir de suposições que são aferidas pela documentação. Ou seja, a partir de rastros e restos desse passado que permaneceram durando e que chegaram até o presente como índices de reconhecimento de fiabilidade desse mesmo passado. 
Pensar o contexto é, portanto, colocar em evidência os movimentos do tempo que podem ser observados no processo histórico. A história ao relacionar o passado com o presente trabalha o tempo como objetivo em movimento numa tripla dimensão: o tempo organizado como sequência ou transcurso; o tempo organizado como lugar, ou espaço; e o tempo organizado pelas transformações, ou jogo de combinações, ou intensidade (Cardoso, 1988).

Assim, o espaço onde se movimentam os atores fundamentais nos processos históricos nada mais é do que uma organização particular do tempo, da mesma forma que as transformações observadas podem ser percebidas como combinações nas quais a intensidade ou os tempos menos velozes, quase imóveis, são também fundamentais para a análise.

A abordagem histórica pressupõe como condicionante fundamental dizer sempre respeito a ações humanas. Mesmo quando o foco da pesquisa recai, por exemplo, sobre um veículo de comunicação estão envolvidas na intepretação realizada as transformações produzidas pelo e a partir do agir humano. As ciências humanas estudam o homem em sua especificidade humana. Portanto, os processos históricos a que nos referimos dizem respeito às transformações realizadas pelo ato performático do homem em ação no tempo. São suas ações, suas práticas, suas apreensões de sentido que formam o arcabouço histórico indispensável para a produção de uma análise numa dimensão contextual.

Se considerarmos, como Agnes Heller, que historicidade não é "[...] aquilo que acontece conosco, tampouco alguma coisa na qual entrássemos como uma vestimenta" (Heller, 1993, p. 389), mas como consciência de nossa existência, há que considerar que a ação do homem no mundo se faz sempre num espaço-tempo. Historicidade é a percepção humana durando, colocando em proeminência formas de vida, enfim, é a consciência sobre o ser. E não há possibilidade de pensa-la fora do tempo e do espaço. "Até mesmo o absurdo é temporal e espacial, porque nós somos tempo e espaço" (Heller, 1993, p. 14).

A consciência humana no tempo, que faz com que haja um limite entre o que fomos e o que seremos, coloca em destaque também o fato de estar no mundo. Ser significa estar aqui. "Somos mortais, mas não estamos mortos. Não podemos conceber o estarmos mortos, posto que somos tempo e espaço" (Heller, 1993, p. 14).

A dimensão espacial significa, portanto, a percepção da humanidade. Uma percepção que se produz temporalmente. Um tempo que passa indicando a presença de outros seres que estarão nos lugares daqueles que viveram outrora. Se, como diz Heller (1993), naquele tempo havia um homem, significa que existiu alguém, no espaço e no tempo, narrando a sua história que será depois contada por outros homens. 
A pergunta mais fundamental da historicidade - o que somos, de onde viemos e para onde vamos? - se faz pela inclusão da categoria espaço, não como território meramente físico, mas como lugar de significações da vida humana.

Nos moldes da historicidade, o tempo também é espaço. Ao se buscar o início, que demarca o lugar físico de quem estava lá, produzindo com sua presença o testemunho, momentos de presença que se deixam emergir por atos de historicidade são espacialmente construídos. É o espaço, ou melhor, o espaço-tempo que demarca as maneiras como nos sentimos históricos e como se constrói a consciência histórica.

Há que se considerar, ainda, que a dimensão do espaço como lugar está presente na própria concepção de tempo linear, indicando a passagem dos dias, dos meses, dos anos e das épocas. O tempo calendário, fundamental para a narrativa histórica, se estrutura de maneira encadeada e no qual cada evento ocupa um lugar específico. Esse lugar previamente demarcado possui a intencionalidade que permite, mais do que a sua localização na relembrança, caracterizar durações com conteúdos diferentes como passado, presente e futuro (Ricoeur, 1997, p. 59).

A narrativa histórica, assim, introduz na trama textual a espacialidade dos tempos de outrora, isto é, a espessura do tempo como espaço de possibilidades, mas que só existe na narrativa. Abre-se, pela narrativa, janelas em direção a um espaço-tempo que é reavivado pelas histórias contadas. O presente em direção ao passado. Do presente ao passado, de um espaço a outro.

\section{O mundo dos escravos como contexto comunicacional}

Como aplicar essa perspectiva do contexto numa dimensão histórica às abordagens comunicacionais? Num estudo publicado recentemente sobre a relação dos escravos com o mundo da comunicação no século XIX (Barbosa, 2016) há um exercício nessa perspectiva metodológica.

Ao invés de discorrer páginas e páginas sobre o mundo do século XIX, o livro centra sua análise no contexto de vida dos escravos em diversas espacialidades geográficas no território chamado Brasil para evidenciar temporalidades marcadas por ações comunicacionais.

Se esse é o movimento realizado inicialmente, no qual os tempos de vida dos escravos passavam da mutabilidade ao embaralhamento de percepções das suas ações de vida para atingir, finalmente, o estágio dos tempos ruidosos (Barbosa, 2013), no momento seguinte são os territórios que se constituem em foco da análise. Esses territórios são marcados pela ideia de contexto comunicacional, no qual as práticas discursivas produzem ações reais e simbólicas em torno da oralidade, da leitura e da escrita. 
Ou seja, ao invés de nos determos na perspectiva de um contexto como mundo econômico, social, político etc., construímos uma lógica reflexiva na qual as ações de comunicação vividas no espaço-tempo constroem contextos comunicacionais.

Num primeiro momento, nos territórios da incerteza (Barbosa, 2016, p. 21) observa-se uma tripla dimensão do tempo na forma como os escravos viviam o seu cotidiano: o tempo após a travessia do Atlântico produzia na sua chegada a mutabilidade duradoura das suas práticas comunicacionais; os tempos embaralhados quando começavam a compreender a língua e produziam astúcias; e, finalmente, os tempos ruidosos em que suas práticas cotidianas se condensavam nos múltiplos burburinhos entabulados nos espaços urbanos. Nesse momento, novos sentidos de tempo começam a se anunciar e, em consequência, praticam e habitam os espaços de maneira peculiar. Em atos comunicacionais duradouros, impõem suas presenças nas cidades tomadas pelos ruídos de suas falas e gritos, insinuando a existência de outro tempo vivido.

Assim, a referência frequente aos gritos, aos risos, às brigas, aos múltiplos contatos no espaço externo mostra como os escravos passam a habitar e ressignificar as ruas. Os atos simbólicos, interferências sonoras e a presença visual indicam ações de comunicação nas quais se podem ver também os passos de uma oralidade complexa.

Gente correndo e andando na cidade, transformando suas ruas e vielas em território dos negros. Os gritos são presença constante. Apropriando-se das cidades, os escravos se inscrevem no espaço nele se fixando. Ao burburinho de vozes e das suas práticas cotidianas, acrescenta-se a movimentação de corpos que escapam à disciplina, apropriando-se das cidades.

Na praça e em volta da igreja, havia um movimento confuso de feira. Negros nos mais coloridos e berrantes trajes de festa empurravamse e corriam, com barulho e gritos estridentes [...] Pequenos grupos fornecedores de cachaça formavam as ilhas, no mar de pessoas. Um palanque, semelhante àquele erigido para o Imperador, na praça do Teatro, anunciava coisas maravilhosas para a tarde que se aproximava (Habsburgo, 1982, p. 92).

A descrição da festa do Bonfim, na década de 1860, feita pelo príncipe Habsburgo, destaca o movimento resultante das aglomerações em torno da praça da igreja e sobressai o movimento dos corpos, sugerindo a brincadeira dos grupos nas ruas. Que sentido teriam os empurrões e a corrida, seguidos de gritos estridentes? A ação deixa ver a partilha de gestos e a alegria denotada pelos gritos em ruas ocupadas a partir de práticas cotidianas. 
Énesse contexto comunicacional que podem ser observadas a apropriação temporal e espacial dos grupos de escravos que habitavam as cidades e que com seus gestos alteravam a retórica do espaço. Correndo em grupos, gritando, modificam a ordem da cidade, reunindo-se e fazendo das ruas o lugar possível de realizar sua comunicação. As ruas são pautas de uma escrita que se faz pelos gestos (Barbosa, 2016).

Durante três séculos o Brasil recebeu, segundo estimativas, 1 milhão de escravos vindos de diferentes lugares da África. Aqui produziram modos duradouros de comunicação, misturando as suas práticas orais extremamente complexas modos letrados de comunicar. Sabiam ler, escrever e contar. Tinham habilidades que os faziam ocupar profissões pouco prováveis, como por exemplo, livreiros, amanuenses, carpinteiros, mestres chapeleiros, entre dezenas de outras, que mostram o imperativo de manejarem a leitura e a escrita. Vez por outra, podemos ver as assinaturas que postavam nas cartas de alforria e em outros papéis. Podemos ver também as cartas que escreveram, os poemas que construíram, as escritas de si mesmo, sobre um si mesmo e muitas vezes para outros (Barbosa, 2016).

Esses modos de comunicação constituem-se territórios tempo-espaciais formando um contexto comunicacional. Percorrendo suas ações e reações, percebendo os gestos significantes, pode-se remontar territórios de práticas comunicacionais que começam com gestos da oralidade, continuam com a percepçãodesuas práticas letradase leitoras eavançam pelosterritórios daescrita.

A música é uma das referências mais constantes no território de vida dos escravos. Utilizando-a como cântico de trabalho, como de oração, nos momentos de lazer, na cantilena da vida diária, em grupo ou individualmente, fazem dela o elemento mais constante de sua comunicação partilhada. $O$ arsenal de sua cultura oral - que podemos denominar territórios da oralidade - se constitui em narrativas rítmicas capazes de permitir o armazenamento de materiais na memória (Havelock, 1995, p. 17-34).

Quando escravos de uma mesma casta trabalham juntos, eles se movimentam ao som de certas palavras, entoadas numa cadência melancólica, começando numa nota mais aguda e terminando numa mais grave. Formando uma longa fila, carregando coisa na cabeça, eles cantam enquanto caminham, e isso pode ser visto todos os dias em quase todas as ruas do Rio. Parecia-me tratar-se de uma espécie de canção nacional, e fiquei particularmente curioso para saber o seu significado, mas ninguém soube interpretar as palavras para mim; e os negros, quando consultados, não quiseram dizer ou fingiram não saber, como se tratasse de algo secreto, do qual fizessem mistério. (Walsh, 1985, p. 156). 
Na descrição do reverendo Robert Walsh, observa-se a repetição do canto como parte das ações as mais diversas. O canto constitui uma espécie de voz duradoura, através da qual estabelecem partilhas e diálogos uns com os outros. A música como território de pertencimento é utilizada com múltiplos propósitos: não apenas para introduzir o tempo do lazer, mas também o do trabalho. Os lamentos sincopados que o viajante escuta são cânticos de trabalho. Esses cânticos, se por um lado induzem a cadência dos gestos, também permitem aos escravos suportar as atividades penosas e desenvolvidas durante muitas horas do dia. Carregando peso, cantam enquanto caminham. A língua que entoam é estranha para os que estão à margem do grupo, como Walsh. As palavras que se esparramam pelos ambientes causam curiosidade no reverendo, mas não há entre os escravos a disposição de partilhar um saber exclusivo do grupo. $O$ segredo guardado é maneira de construir, na contingência da conjuntividade (Heller, 1993), um espaço de comunicação inteligível apenas para eles.

Se os territórios da oralidade nos levam para os ambientes das ruas da cidade, onde as práticas de comunicação são partilhadas, mas, ao mesmo tempo, difíceis de serem recuperadas, já que são ações sem a inscrição duradoura, os territórios da leitura constituem um contexto passível de ser interpretado a partir de múltiplas inscrições.

Imagensvisuaisasmaisdiversasmostram, inicialmente,aimposiçãogradual de uma ordem letrada que se esparrama pela sociedade. Desenhos de viajantes revelam indícios das práticas letradas se espalhando pelo território. Ao mesmo tempo, em diversas cidades, após 1820, há o aparecimento de diversos periódicos formando redes de comunicação de Norte ao Sul do território (Barbosa, 2013).

Esseé o contexto comunicacional que envelopa os territórios da leitura dos escravos brasileiros. E buscando os rastros existentes nesse mundo presumido como realidade, surgem imagens e textos na trama da documentação (cartas de alforria, processos penais, testamentos, romances de época, periódicos etc.) que mostram o mundo do letramento fazendo parte do mundo dos escravos.

Nas descrições dos anúncios que seguidamente procuram pelos que fugiam do cativeiro, por exemplo, há a indicação do ato de saber ler e escrever como habilidade específica, o que os colocam também nos territórios da leitura e da escrita. Há também a explicitação de suas práticas profissionais para as quais eram necessárias habilidades cognitivas do mundo do letramento.

Já os territórios da escrita se projetam como a complexificação do mundo da leitura. Se a carta de alforria tornava a liberdade um território da escrita, os indícios dessa territorialidade se mostravam nos papéis que muitos carregavam junto aos corpos, na descrição de suas práticas de leitura e escrita e, sobretudo, 
nas cartas que escreveram e que evidenciam sentidos múltiplos quase dois séculos depois de sua composição.

\begin{abstract}
Meo filho eu es de ti ma muito a sua sau de conno para mim dezeio noto bem $p$ avo es mi mandra comta como vai seu sau de no mais eu bos to a minha bremcao Deos te a be so para muito tempo ti de sau de como para mim deze no to bem para sou a tua maiti a dora no mais a $\operatorname{Deos}^{3}$ (Wissenbach, 1998, transcrito por Oliveira, 2009, p. 218).
\end{abstract}

Na carta escrita pelo escravo Claro a pedido de Teodora (uma das sete que escreveu para a escrava) os signos de uma oralidade duradoura se mostram evidentes: só lendo em voz alta é possível decifrar o que foi escrito. Além disso, observa-se os sentidos atribuídos a escrita pelos escravos. Para Teodora e para Claro, as letras escritas eram capazes de ultrapassar o espaço-tempo e encontrar aqueles que estavam distantes.

Observamos também as fórmulas presentes na escrita epistolar, na qual é indispensável um texto introdutório desejando votos, sobretudo, de saúde para os que teriam contato com aqueles textos. Na carta, Teodora só quer saber notícias do filho e declarar sua afeição. Abençoa-o, deseja saúde, reafirma a sua estima e adoração. Jamais saberemos como era Inocêncio, quanto tempo a escrava não o via. Mas sabemos pela fixação de sua emoção na carta escrita por outrem os sentimentos que a dominam naquele momento. $O$ desejo do bem, do reencontro, que pela escrita se torna de alguma forma possível, são signos de um afeto que se torna perene pelo ato escriturário.

\title{
llação
}

A presente pesquisa, nessa primeira tentativa de juntar ideias acerca da historicidade e do contexto nos ambientes da história e da comunicação, nos apresenta possibilidades antes não aventadas: de um lado, as proposições que se colocam disponíveis para repensar a historiografia a partir da essência do histórico que provoca mutabilidades estruturais nas sociedades; de outro, a certeza de que o contexto é texto, é língua, é narrativa e se constitui de modos de revelação; e, por fim, a compreensão de que a historicidade nem sempre atende à singularidade que tem marcado os campos da história e da comunicação (jornalismo).

Nem sempre é o ser essencialmente singular que provoca mutações também singulares que atravessam o tempo e o espaço, mas o não ser ou até

3 "Meu filho estimado muito e a sua saúde como para mim desejo noto bem. Me manda contar como vai de saúde, no mais eu boto a minha benção. Deus te abençoe por muito tempo, te dê saúde como para mim desejo, noto bem. Sou a tua mãe que te adora. No mais, adeus" (transcrição da autora). 
mesmo o nada pode também tudo ultrapassar para chegar ao íntimo do seu ser, deixando de algum modo transparecer sua essência. Essência que será revelada pela aparência, pelo aparecer, pelo se colocar no mundo, confirmando sua existência, através dos modos de agir e de representar esse agir.

Recorremos ao conceito de historicidade para ressignificar discursos e lugares dos povos na história, neste artigo, especificamente, da história dos negros escravizados no Brasil. Foi através de um novo olhar para a trajetória desse povo e os contextos de sua existência, reveladores de sua essência, que chegamos a compreender que a historiografia ainda encontra-se bem distante de contemplar as historicidades perdidas ou relegadas ao esquecimento.

Se entre historicidade e historiografia existem hiatos não contemplados, muitas vezes não resolvidos, nem mesmo passíveis de solução; também existem pontos de convergência que se interligam através dos contextos. São os vestígios, os rastros e as diversas outras formas de localização das sociabilidades, dos modos de ser e de se colocar no mundo que são vasculhados pelos pesquisadores em busca de soluções para as lacunas históricas.

Reconstruir discursos históricos significa reposicionar os povos diante de sua história, significa retirar do anonimato a importância dos subjugados pelo poder, significa dotar de dignidade sociedades dominadas, reforçando sua identidade elevando a autoestima de seus componentes.

A história dos negros escravizados no Brasil esteve sempre à margem de uma história oficial e, portanto, quase que totalmente sem representatividade e sem visibilidade.

Somente em momentos recentes da nossa historiografia o negro renasce através de personagens de projeção (seres dotados de essência do histórico) capazes de mover a sociedade, contudo, nunca como povo importante na constituição do nosso país.

Perceber o grupo é destacar, sobretudo, modos de comunicação como contexto histórico e comunicacional onde cada um vivia e ressignificava sua existência. Procuramos mostrar que a noção de contexto tendo como central a perspectiva de uma historicidade na qual a relação passado, presente e futuro apresenta singularidades construídas pelo arco narrativo que interpreta a vida. Nesse sentido, podemos afirmar que modos de comunicação se transfiguram em territórios tempo-espaciais formando contextos comunicacionais relacionados diretamente aos modos como se operacionaliza o ser no tempo.

Como exercício metodológico, apresentamos gestos de comunicação dos escravos formulando e formatando um contexto de particularidades narrativas que se configura como um contexto comunicacional. Pelos atos narrativos, os escravos escreveram textos como modos de comunicação, ao se moverem em 
territórios de significações espaço temporais. Dessa forma, apresentamos texto e contexto historicamente construídos ao percorrer suas ações e perceber nelas gestos significantes. A partir do ato interpretativo é possível remontar territórios de práticas comunicacionais que começam com gestos da oralidade, continuam com a percepção de suas práticas leitora e avançam nos territórios da escrita.

\section{Referências}

BARBOSA, Marialva. Escravos e o mundo da comunicação. Oralidade, leitura e escrita no século XIX. Rio de Janeiro: Mauad, 2016.

História da comunicação no Brasil. Petrópolis: Vozes, 2013.

BURKE, Peter. O que é história cultural? Rio de Janeiro: Jorge Zahar, 2005.

CARDOSO, Ciro Flamarion. Ensaios racionalistas. Rio de Janeiro: Campus, 1988.

CERTEAU, Michel. A escrita da história. Rio de Janeiro: Forense, 2011.

GADAMER, Hans-Georg. Hegel, Husserl, Heidegger. Petropólis: Vozes, 2012.

GINZBURG, Carlos. A micro-história e outros ensaios. Rio de Janeiro: Bertrand Brasil, 1989.

HABSBURGO, Maximiliano de. Bahia 1869: esboços de viagem. Rio de Janeiro:Tempo Brasileiro; Salvador: Fundação Cultural do Estado da Bahia, 1982.

HAVELOCK, Eric. A equação oralidade-cultura escrita: uma fórmula para a mente moderna. In: OLSON, David Richard; TORRANCE, Nancy. Cultura escrita e oralidade. São Paulo: Ática,1995.

HEGEL, Georg Wilhelm Friedrich. Filosofia da história. Brasília: UNB, 2008.

HEIDEGGER, Martin. Ser e tempo. Petrópolis: Vozes, 2005.

HELLER, Agnes. Uma teoria da história. São Paulo: Brasiliense, 1993.

IBER, Christian. Historicidade da filosofia em Hegel e Heidegger. Revista Opinião Filosófica, Porto Alegre, v. 4, n. 2, p. 24-33, 2013.

KOSELLECK, Reinhart. Estratos do tempo: estudos sobre história. Rio de Janeiro: Contrapondo, PUC-RJ, 2014.

LE GOFF, Jacques; NORA, Pierre. História: novos objetos. Rio de Janeiro: Francisco Aires, 1974. 
OLIVEIRA, Klebson. Textos de escravos no Brasil oitocentista: os tempos de uma edição filológica e de uma antologia comentada de alguns fatos linguísticos. Revista de Filologia e Linguística Portuguesa, São Paulo, n. 10-11, p. 189-220, 2009.

RÊGO, Ana Regina. História, cultura e identidade. In: RÊGO, Ana Regina; MENDES, Cecília e QUEIROZ, Teresinha (Orgs.). Piauí. História, cultura e patrimônio. Teresina: Ed.ICF, 2010.

RICOEUR, Paul. Tempo e Narrativa (v. 3). Campinas: Papirus, 1997.

RICOEUR, Paul. Tempo e Narrativa (v. 1). São Paulo: Martins Fontes, 2010.

RICOEUR, Paul. A memória, a história e o esquecimento. Campinas-SP: Ed. UNICAMP, 2012.

RICOEUR, Paul. $\mathbf{O}$ conflito das interpretações: ensaios de Hermenêutica. Porto: RésEditora, s/a.

SARTRE, Jean-Paul. O ser e o nada. Petrópolis: Vozes, 2015.

TAYLOR, Charles. Hegel: sistema, método e estrutura. São Paulo: Realizações, 2014.

WALSH, Robert. Notícias do Brasil. Belo Horizonte: Itatiaia; São Paulo: Edusp, 1985.

WISSENBACH, Maria Cristina Cortez. Sonhos africanos, vivências ladinas. São Paulo: HUCITEC,1998.

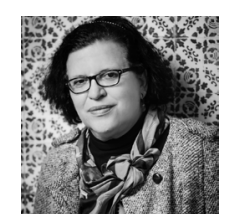

Marialva Carlos Barbosa <marialva153@gmail.com>

Programa de Pós-Graduação em Comunicação da Universidade Federal do Rio de Janeiro (UFRJ)

Avenida Pasteur, 250 - Urca

22290-240 - Rio de Janeiro (RJ) - Brasil

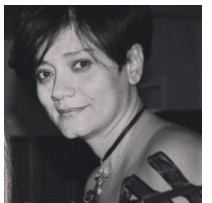

Ana Regina Rêgo <anareginarego@gmail.com>

Programa de Pós-Graduação em Comunicação da Universidade Federal do Piauí (UFPI)

Campus Universitário Ministro Petrônio Portella - Bairro Ininga

64049-550 - Teresina (PI) - Brasil 